JOURNAL OF ARCHITECUTRE AND URBANISM RESEARCH

\title{
Perencanaan Rumah Sakit Umum Type C Di Sulit Air IX Koto Diatas Kabupaten Solok
}

\section{Planning for General Hospital Type C In Difficult Air Ix Koto Above Solok Regency}

\author{
${ }^{*}$ Lidya Sari $\left.{ }^{1}\right)$, Irnawati Siregar²) \& Elviyanti³)
}

1)Mahasiswa Prodi Arsitektur Fakultas Teknik Dan Perencana Universitas Ekasakti, Indonesia 2, 3) Dosen Prodi Arsitektur Fakultas Teknik Dan Perencana Universitas Ekasakti, Indonesia

Diterima: Februari 2020; Disetujui: April 2020; Dipublikasi: 30 April 2020

*Corresponding author: E-mail : lidyasari1906@gmail.com

\begin{abstract}
Abstrak
Penelitian ini bertujuan untuk merencanakan pembangunan Rumah Sakit Umum Type C guna mewujudkan derajat kesehatan yang optimal bagi masyarakat yang ada di daerah Kota maupun Kabupaten. Kabupaten solok yang terdiri dari beberapa wilayah salah satunya nagari Sulit Air IX Koto Diatas sangat membutuhkan akan pelayanan kesehatan berupa Rumah Sakit Umum karena kurangnya akan pelayanan kesehatan yang memadai. Perencanaan Rumah Sakit Umum ini menggunakan metode penelitian kualitatif dengan pendekatan Deskriptif Analitik dengan melakukan pengumpulan data primer dan data sekunder. Perencanaan ini memakai konsep Green Architecture, sehingga dapat mewujudkan suatu landasan yang konseptual bagi perencanaan Rumah Sakit yang nyaman dengan memperhatikan tatanan massa bangunan dan Open Space yang lebih luas dan menerapkan unsur-unsur yang harus dipenuhi dalam perancangan Rumah Sakit.
\end{abstract}

Kata Kunci : Sulit Air IX Koto Diatas, Rumah Sakit Umum, Green Architecture

\section{Abstract}

This research aims to plan the construction of a General Hospital Type $C$ in order to realize the optimal degree of health for people who there are cities and regencies in the district of Solok consisting of some areas one of them is Nagari difficultAir X Koto Above very need health services in the form of General Hospital because lack of adequate health services Hospital Planning This general uses qualitative research methods Analytical descriptive by collecting primary data and data secondary. This planning uses the concept of Green Architecture, so it can creating a conceptual foundation for Hospital planning comfortable with marrying out the building mass order and the open Space broader and apply elements that must be met in the design Hospital.

Keywords: Difficult Air IX Koto Above, General Hospital, Green Architecture

How to Cite : S. Lidya, Irnawati S, Elviyanti , (2020), Perencanaan Rumah Sakit Umum Type C di Sulit Air IX Koto di atas Kabupaten Solok, J ournal of Architecture and Urbanism Research, 3 (2): Hal 124-128. 


\section{PENDAHULUAN}

Indonesia merupakan salah satu negara yang menjamin kesehatan bagi setiap warganya melalui konstitusi dalam UU No.23 Tahun 1992 yang menyatakan bahwa kesehatan adalah merupakan hak asasi manusia. Hal yang sama dimuat dalam Undang-Undang No. 36 tahun 2014, kesehatan adalah keadaan sehat, baik secara fisik, mental, spritual maupun sosial yang memungkinkan setiap orang untuk hidup produktif secara sosial dan ekonomis, dimana pemerintah bertanggung jawab atas penyediaan pelayanan kesehatan berupa pembangunan rumah-rumah sakit dan pelayanan kesehatan lainnya.

Pembangunan Pelayanan kesehatan sudah dilakukan dipusat kota dan wilayah sekitarnya berupa rumah-rumah sakit dengan berbagai tipe Rumah Sakit yang telah diatur oleh undang-undang, serta pembangunan Puskesmas yang juga dilengkapi dengan Pukesmas Pembantu. Berbeda halnya di wilayah Kabupaten pada umumnya hanya diberikan pelayanan kesehatan berupa Puskesmas. Pelayanan kesehatan di nilai sangat penting mengingat perkembangan berbagai jenis penyakit yang tidak hanya bisa di tangani oleh Puskesmaspuskesmas sehingga memerlukan rujukan pengobatan ke Rumah Sakit.

Kabupaten Solok yang terdiri dari beberapa kenagarian, salah satunya Nagari Sulit Air IX Koto Diatas yang terdiri dari 3 Nagari dan 22 Jorong (Nagari Sulit Air 13 jorong, Nagari Bukit kandung 5 jorong dan Nagari Pasilihan 4 jorong), dengan jumlah total penduduk 9.874 jiwa/2.859 KK (Profil Puskesmas Sulit Air 2014). Daerah Sulit Air IX Koto Diatas terdapat satu Pusat Pelayanan Kesehatan Masyarakat (PUSKESMAS). Secara geografis Puskesmas Sulit Air berada di kawasan perbukitan, terletak 55 km dari pusat Kabupaten Solok
(Kayu Aro) dan $96 \mathrm{~km}$ dari pusat Provinsi Sumatera Barat (Padang).

Berdasarkan pergerakan jumlah masyarakat yang datang ke Puskesmas Sulit Air dalam lima tahun terakhir, mulai pada tahun 2015 jumlah pengunjung Puskesmas Sulit Air yaitu sebanyak 6.057 orang (Data Dasar Puskesmas Sumbar, 2015), pada tahun 2016 terjadi peningkatan yang sangat signifikan yaitu sebanyak 12.474 orang (Data Dasar Puskesmas Sumbar, 2015), sedangkan pada tahun 2017 jumlah masyarakat yang datang ke Puskesmas Sulit Air menjadi berkurang yaitu sebanyak 5.598 orang, ini disebabkan kurangnya pelayanan dan dokter yang menangani penyakit tertentu sehingga masyarakat cendrung datang kerumah sakit di Kota madya.

Berdasarkan data dan studi prapenelitian serta permasalahan yang ada maka sudah selayaknya dilakukan perencanaan perancangan Rumah sakit Umum di Sulit Air IX Koto Diatas Kabupaten Solok. Type Rumah Sakit Umum yang direncanakan adalah Type C sebagaimana yang telah ditetapkan oleh Departemen kesehatan RI Jl. Prapatan No. 10 Jakarta, 1978 bahwa pembangunan Rumah Sakit Umum Type C didirikan disetiap ibukota dan kabupaten guna memenuhi kebutuhan pelayanan masyarakat di wilayah tersebut.

\section{METODE PENELITIAN}

Jenis penelitian pada perencanaan Rumah Sakit Umum Type C di Sulit Air IX Koto Diatas Kabupaten Solok, adalah penelitian kualitatif dengan pendekatan Deskriptif Analitik. Penelitian kualitatif dengan prosedur penelitian yang mengumpulkan data deskriptif berupa katakata tertulis atau lisan dari orang-orang dan 
prilaku yang dapat diamati (Lexi. J. Moleong, 2005 : 132).

Deskriptif Analitik adalah suatu metode yang berfungsi untuk mendeskripsikan atau memberi gambaran terhadap objek yang diteliti melalui data atau sampel yang telah terkumpul sebagaimana adanya tanpa melakukan analisis dan membuat kesimpulan yang berlaku untuk umum (Sugiono, 2009; 29).

Menurut Suharmisi Arikunto (2002 : 96) Data penelitian adalah segala fakta dan angka yang dapat dijadikan bahan untuk menyusun suatu informasi.

Data Primer pada penelitian ini adalah pengunjung rumah sakit baik berupa kata-katanya dan perilaku hariannya, seperti yang disebutkan Sugiyono (2012).

Data Sekunder, pada penelitian ini diperoleh dari Jurnal, Buku dan Literatur lainnya yang berkaitan dengan penelitian Rumah Sakit Umum Tipe C

\section{HASIL DAN PEMBAHASAN}

Analisa Tapak Perencanaan, analisa tapak digunakan dalam suatu perancangan kota non fisik dan digunakan juga untuk merumuskan program ruang berdasarkan karakteristik aktifitas pengguna dan aktivitas ruang.

Pemilihan lokasi tapak bangunan Rumah Sakit Type C yang direncanakan dapat ditentukan berdasarkan beberapa kriteria dengan pertimbangan sebagai berikut:

a) Luas tapak, sesuai dengan kebutuhan perencanaan Rumah Sakit Umum Type C dengan luas minimum yaitu 3 hektar.

b) Aktifitas sekitar tapak relatif tidak padat.

c) Kepadatan aktifitas pada sekitar tapak perencanaan hanya akan memberi dampak tidak nyaman yang justru mengakibatkan gangguan kelancaran arus lalulintas di sekitar tapak perencanaan.

d) Pencapaian dan sirkulasi, Kemudahan dalam pencapaian site menjadi salah satu hal penting dalam menentukan tapak perancangan, pencapaian yang sulit terhadap tapak hanya akan mengurangi minat masyarakat yang datang untuk berobat.

e) Lokasi yang strategis, Kondisi lokasi yang strategis dibutuhkan untuk memberikan kenyaman pada pengunjung dan lingkungan sekitar.

f) Dekat dengan fasilitas penunjang lainnya, ada beberapa fasilitas yang diwadahi dalam perancangan ini, maka perlu adanya fasilitas-fasilitas penunjang lainnya yang berada dikawasan tapak perancangan yang mendukung pada objek perancangan.

Konsep Desain, secara tema perancangan yang digunakan pada perencanaan Rumah Sakit Umum Type C di Sulit Air IX Koto Diatas Kabupaten Solok adalah Green Architecture. Green Architecture adalah konsep arsitektur yang berusaha meminimalkan pengaruh buruk terhadap lingkungan alam maupun manusia dan menghasilkan tempat yang lebih baik dan lebih sehat. Penerapan Green Architecture dilakukan dengan cara memanfaatkan sumber energi dan sumber daya alam secara efisien dan optimal.

Prinsip - prinsip Green Architecture adalah sebagai berikut Conserving energy, Memaksimalkan energi alam sekitar lokasi bangunan, seperti: 


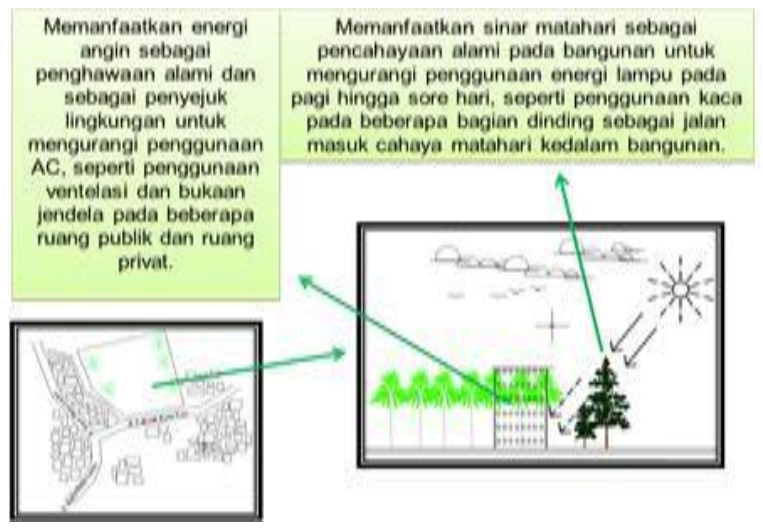

Gambar 1 Conservasi Energi (Sumber: Pengolahan Data)

Working with climate, Mendisain bangunan harus berdasarkan iklim yang berlaku di lokasi tapak dan sumber energi yang ada, seperti:

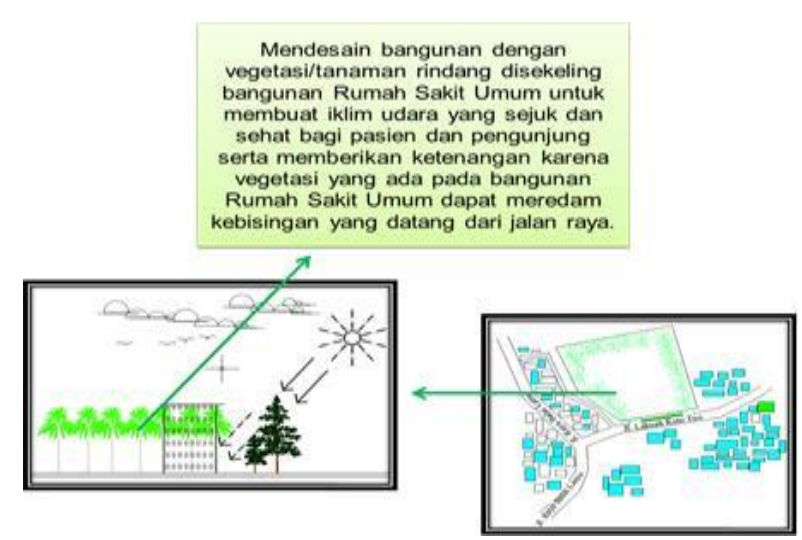

Gambar 2 Working With Climate (Sumber: Pengolahan Data)

\section{Minimizing}

\section{new}

resources,

Mengoptimalkan kebutuhansumberdaya alam yang baru, agar dapat digunakan di masa mendatang, seperti:

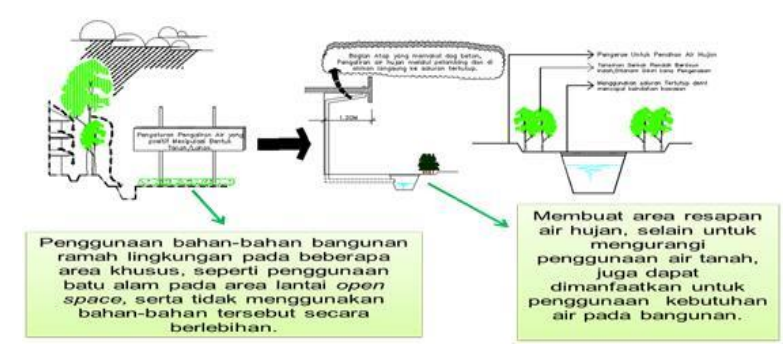

Gambar 3 Minimizing New Resourse

(Sumber: Lidya Sari, 2019)
Respect for site, Tidak merusak lingkungan yang ada dengan cara:

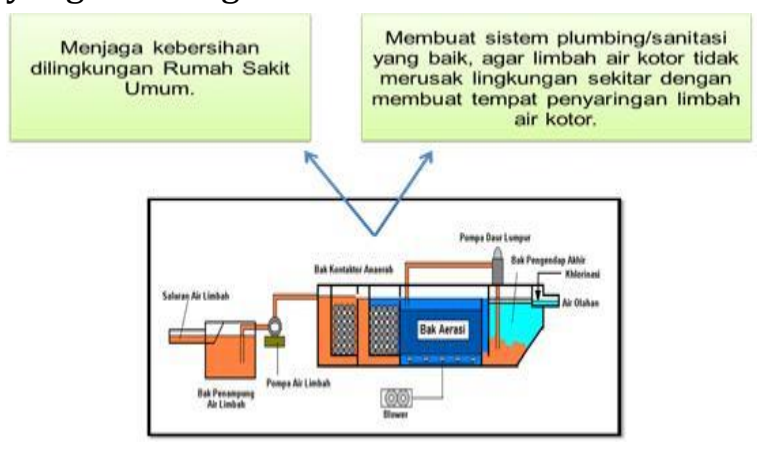

Gambar 4 Respect For Site

(Sumber: Pengolahan Data)

Respect for user, Dalam merancang bangunan harus memperhatikan semua pengguna bangunan dan memenuhi semua kebutuhannya. Penerapannya seperti Membuat jalur khusus pejalan kaki untuk pencapaian menuju banguan.

Holism , Menetapkan prinsip - prinsip Green Architecture pada beberapa aspek perencanaan, seperti pada pencahyaan, penghawaan bangunan serta penggunaan material yang ramah lingkungan.

\section{SIMPULAN}

Perencanaan perancangan Rumah Sakit Umum Type C selanjutnya lebih memperhatikan tatanan massa bangunan dan open space yang lebih luas. Metode yang digunakan adalah Metode Kualitatif dan Deskriptif Analitik sehingga menghasilkan suatu rancangan Rumah Sakit Umum Type $\mathrm{C}$ yang nyaman bagi pasien dan pengunjung Rumah Sakit. 
DAFTAR PUSTAKA

F.D Ching, Arsitektur bentuk, Ruang dan Tatanan. Ciracas: Penerbit Erlanga, 2008.

Dinas Kesehatan, Profil Kesehatan Provinsi Jawa Timur Th. 2011 Uma Etica Para Quantos, 2012.

Haryadi dan B.Setiawan, Arsitektur, Lingkungan, dan Perilaku, Yogyakarta: Gajah Mada University Press, 2010.

P.R Indonesia, Undang-Undang No. 23 Tahun 1992 tentang Kesehatan (23), 1992.

J.S Juwana, Paduan Sistem Bangunan Tinggi. Ciracas: Penerbit Erlanga, 2005.
Kemenkes RI Data Dasar Puskesmas, In Journal of Chemical Information and Modelling (Vol 53), 2013.

Kesehatan D \& Solok K (2014) Solok tahun 2014

M. Karlem, Dasar-dasar Perencanaan Ruang. Ciracas: Penerbit Erlanga, 2007.

Neufert and Ernst., Data Arsitek jilid I Edisi 33, Terjemahan Sunarto Tjahjadi. Jakarta : Erlangga, 1996.

Neufert and Ernst., Data Arsitek jilid II Edisi 33, Terjemahan Sunarto Tjahjadi. Jakarta : Erlangga, 1996.

Presiden RI Undang-Undang RI Nomor 36 Tahun 2014 tentang Tenaga Kesehatan Presiden Republik Indonesia, 2014. 